OPEN ACCESS

Edited by:

Sungsoo Park

Korea University, South Korea

Reviewed by:

Leandro Cardoso Barchi, University of the Sciences,

United States

Kleanthis Giannoulis, Aristotle University of

Thessaloniki, Greece

*Correspondence:

Kun Yang

yangkun068@163.com

tThese authors have contributed equally to this work and share first

authorship

Specialty section:

This article was submitted to

Surgical Oncology,

a section of the journal

Frontiers in Surgery

Received: 12 June 2021 Accepted: 29 November 2021 Published: 24 December 2021

Citation:

Zhang Y-X, Liu H-D, Chen Z-H, Jin T,

Hu J-K and Yang $K$ (2021)

Comparison of Survival and Safety Between Total Omentectomy and Partial Omentectomy for Gastric

Cancer: A Meta-Analysis.

Front. Surg. 8:708545.

doi: 10.3389/fsurg.2021.708545

\section{Comparison of Survival and Safety Between Total Omentectomy and Partial Omentectomy for Gastric Cancer: A Meta-Analysis}

\author{
Yue-Xin Zhang ${ }^{1,2+}$, Han-Dong $\mathrm{Liu}^{3 \dagger}$, Ze-Hua Chen ${ }^{1,2}$, Tao Jin ${ }^{1,2}$, Jian-Kun Hu ${ }^{1,2}$ and \\ Kun Yang ${ }^{1,2 *}$
}

${ }^{1}$ Department of Gastrointestinal Surgery, West China Hospital, Sichuan University, Chengdu, China, ${ }^{2}$ Laboratory of Gastric Cancer, State Key Laboratory of Biotherapy/Collaborative Innovation Center of Biotherapy and Cancer Center, West China Hospital, Sichuan University, Chengdu, China, ${ }^{3}$ Department of Gastrointestinal Surgery, West China Hospital Sichuan University Jintang Hosptial, Chengdu, China

Background: The greater omentum can limit abdominal inflammation and act as a protective cushion, but it is always involved in dissemination of gastric cancer. The purpose of this meta-analysis was to compare the survival and safety between total omentectomy and partial omentectomy for gastric cancer.

Methods: Two investigators independently conducted a systematic search of PubMed, Embase, CNKI, and Cochrane Library ranging from January 2000 to November 2020. The pooled odds ratio (ORs) and weighted mean difference (WMD) with the 95\% confidence interval $(95 \% \mathrm{Cl})$ were used to assess perioperative and survival parameters.

Results: A total of 2,031 patients in 11 studies (574 patients in the partial omentectomy group and 1,457 patients in the total omentectomy group) were included. The results found shorter operation time $(\mathrm{WMD}=-25.584 ; P=0.000)$ and less intraoperative blood loss $(\mathrm{WMD}=-47.301 ; P=0.050)$ in the partial omentectomy group, compared to total omentectomy. There were no significant differences in terms of incidence of complications ( $\mathrm{OR}=0.770 ; P=0.164)$, blood transfusions rates $(\mathrm{OR}=0.269 ; P=$ $0.161)$, time to first flatus $(\mathrm{WMD}=0.160 ; P=0.345)$, hospital stay $(\mathrm{WMD}=-1.258 ; P$ $=0.087$ ), and number of harvested lymph nodes (WMD $=1.265 ; P=0.662)$. For the disease-free survival $(\mathrm{OR}=0.80 ; P=0.381)$ and overall survival, there were no statistical differences between the two procedures.

Conclusions: The partial omentectomy could reduce operation time and trended to decrease intraoperative blood loss. And the survival in patients with partial omentectomy seemed to be comparable to that of patients with total omentectomy.

Keywords: total omentectomy, partial omentectomy, gastric cancer, survival, safety 


\section{INTRODUCTION}

Gastric cancer is one of the most common cancers in the world. Surgery takes the core position of treatment of gastric cancer; the prognosis of patients with gastric cancer is closely correlated to the radicality of resection of gastric cancer.

Complete resection of the greater omentum was considered to be the key to ensuring the elimination of micrometastasis (1), because the greater omentum is closely associated with the intraperitoneal spread of gastrointestinal malignant tumors $(2,3)$. And lymph node metastasis in the greater omentum could lead to recurrence (4), whereas partial omentectomy (PO) might compromise the lymph node dissection. As a mesenteric tissue, however, the greater omentum contains a large number of immune cells, which helps to prevent intestinal adhesion and eliminate abdominal inflammation (5). Other advantages of preserving the greater omentum include shortening operation time and reducing complications, especially in the popular laparoscopic gastrectomy where the risks of spleen and colon injury were greatly increased (6). On the other hand, a prospective, observational cohort study [OMEGA trial (7)] included 100 patients with gastric cancer with total omentectomy (TO), and it found rare patients had positive omental metastasis in the postoperative pathological report. And if there was micrometastasis of gastric cancer cells in the greater omentum, the clinical stage of the patients should be stage IV, and total omentectomy cannot improve the survival of patients theoretically. Therefore, whether patients can actually benefit from total omentectomy, especially for advanced cases and patients receiving laparoscopic gastrectomy, remains unclear. Meanwhile, clinical guidelines across the world related to omentectomy during gastrectomy are inconsistent. The latest NCCN gastric cancer guideline recommended the removal of both the greater omentum and the lesser omentum (8), but the European guidelines did not give any recommendations for omentectomy (9). According to current Japanese guidelines for gastric cancer, partial omentectomy can be performed in T1 and $\mathrm{T} 2$ tumors, but this was not the standard procedure for $\mathrm{T} 3$ or deeper tumors (10).

Therefore, the purpose of this meta-analysis was to evaluate the differences in survival, complications, operation time, and operation related parameters between total omentectomy and partial omentectomy in gastric cancer patients, aiming at guiding the surgical treatment of gastric cancer and pointing out the direction of future research.

\section{METHODS}

This meta-analysis was conducted by the reporting guidance to PRISMA (11). Since identifiable patient personal information was not involved, this systematic review and meta-analysis did not require ethical approval.

Abbreviations: PO, partial omentectomy; TO, total omentectomy; NOS, Newcastle-Ottawa Scale; RCT, randomized controlled trial; WMD, weighted mean difference; OR, odds ratio; OS, overall survival; DFS, disease-free survival; RFS, recurrence free survival; $\mathrm{CI}$, confidence intervals.

\section{Search Strategy}

Two investigators individually searched the PubMed, Embase, CNKI, and Cochrane databases using the terms (stomach OR gastric) AND (cancer OR carcinoma) AND (omentectomy OR omentum-preserving OR omentum-preserved OR omentum resection), regardless of language. The electronic search was up to November 2020. The controlled trials comparing total omentectomy to partial omentectomy in gastric cancer surgery were eligible. Conference data and gray literatures were also included if any.

\section{Inclusion Criteria}

The inclusion criteria for the studies were as follows:

1. Patients with gastric adenocarcinoma;

2. Study should include data comparing total omentectomy and partial omentectomy in patients with gastric cancer;

3. The included patients should receive radical surgery and appropriate lymph node dissection;

4. Either distal gastrectomy or total gastrectomy was included;

5. Either early cancer or advanced cancer was included;

6. Either open surgery or laparoscopic surgery was included;

7. Essential information such as postoperative comorbidities, mortalities or survival outcomes were reported.

\section{Exclusion Criteria}

Studies that met the following criteria were excluded:

1. Studies without control groups;

2. Case reports, reviews, letters, and comments;

3. Lack of necessary data for statistical analysis;

4. The pathological types of cancer cells in the patients were gastric stump cancer, lymphoma, and neuroendocrine tumor etc.;

5. The patients in the literature received neoadjuvant chemotherapy;

6. Patients with distant metastasis, such as peritoneal seeding and liver metastasis.

\section{Data Extraction and Quality Assessment of the Studies}

Two researchers independently extracted data from each study, including publication year, author's name, country, stage of tumor, sample size, the type of operation, operation time, mortality, morbidity, and postoperative survival outcomes. The Newcastle-Ottawa Scale (NOS) was used to assess the methodological quality of non-RCT studies. The NOS evaluated the study based on the selection of study groups, comparability between groups, and exposure/outcomes. Studies with a score of $\geq 6$ were considered to be high quality (12). The Cochrane risk of bias tool was used to assess the methodological quality of RCT studies (13).

\section{Data Analysis}

We used the STATA version 12.0 (StataCorp., College Station, TX) to analyze. The heterogeneity between the studies was tested by Cochran's $Q$ and Higgins's $I^{2}$ statistics. If there was no heterogeneity $\left(I^{2}<50 \%, P>0.10\right)$, a fixed-effect model was used. 


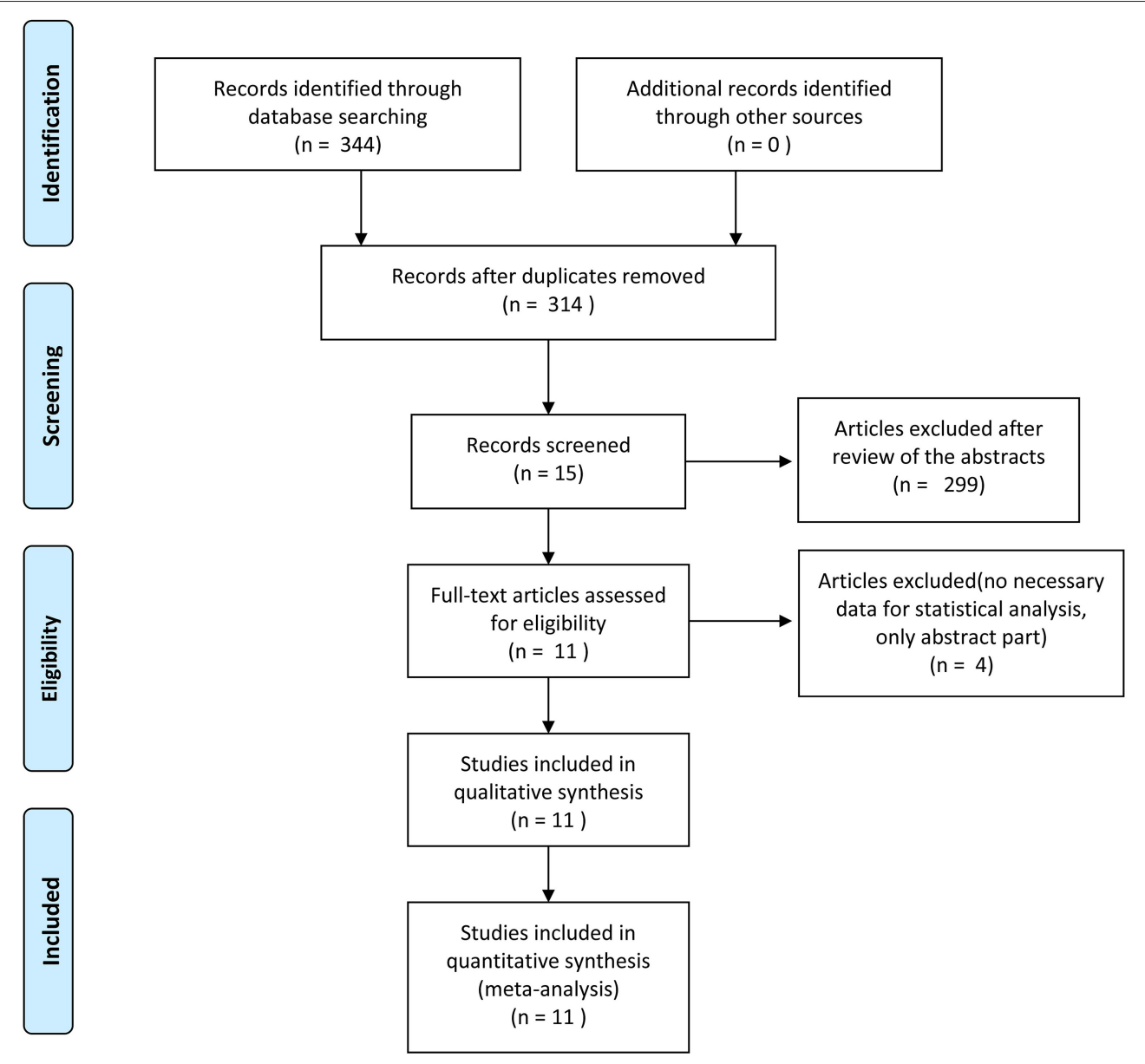

FIGURE 1 | Flow chart for study selection.

If the heterogeneity existed, we adopted three methods to explain heterogeneity: (1) using random-effect model; (2) subgroup analysis stratified by the operation method (laparoscopic vs. open surgery) or stages (early gastric cancer vs. advanced gastric cancer); (3) sensitivity analysis by excluding studies one by one. Dichotomous variables were measured using the odds ratio (OR), and continuous variables were evaluated to obtain the weighted mean difference (WMD) with $95 \%$ confidence intervals (CIs). $P<0.05$ was defined as statistically significant. If the published paper only provides the median, range, and size of the sample, we estimated the mean and variance by transforming the formula (14).

\section{RESULTS}

The flow chart of search strategy is shown in Figure 1. A total of 344 articles were identified after searching the database. After deleting duplicate records, there were 314 articles left. A total of 299 articles were excluded after reviewing the titles and abstracts. Four articles were furtherly excluded since lack of essential data. Finally, 11 articles were included in the analysis. The publication date ranged from 2011 to 2020. According to the NOS, five articles received a score of 5 , one article was scored 6 , and four articles were scored 8 . Ten studies were retrospective cohort studies $(2,15-23)$. One RCT (24), which was evaluated by the Cochrane risk of bias tool, was a conference abstract from ASCO. The RCT had a high risk of bias, mainly due to lack of detailed information, and the biases are expected to be reduced after full publication. The characteristics and quality assessment of included studies are presented in Table 1. A total of 2031 patients were included. With respect to the stage of retrieved cases, eight articles which included 1,443 cases focused on early gastric cancer, and the rest discussed advanced gastric cancer. A total of 574 patients and 1,457 patients underwent partial omentectomy and total omentectomy respectively (Table $\mathbf{1}$ ).

\section{Outcome Measures}

Detailed information is shown in Table 2.

\section{Survival}

The survival rates of patients with gastric cancer, especially those with advanced gastric cancer, was the primary outcome. Only two articles provided postoperative survival information, but we were 
TABLE 1 | Characteristics of patients between total omentectomy and partial omentectomy group.

\begin{tabular}{|c|c|c|c|c|c|c|c|c|c|c|c|}
\hline Author & Year & Country & $\begin{array}{l}\text { Study } \\
\text { design }\end{array}$ & Stage & Group & Cases & Age range (yr) & $\begin{array}{c}\text { Gender } \\
\text { (male/female) }\end{array}$ & $\begin{array}{l}\text { Surgical } \\
\text { procedure }\end{array}$ & Follow-up & $\begin{array}{l}\text { Quality } \\
\text { Scores }\end{array}$ \\
\hline Wang et al. (17) & 2012 & China & NRCT & EGC & $\begin{array}{l}\mathrm{PO} \\
\mathrm{TO}\end{array}$ & $\begin{array}{l}20 \\
20\end{array}$ & $\begin{array}{c}58.6 \pm 10.1 \\
58.2 \pm 9.7\end{array}$ & $32 / 8$ & Open & NA & $5 / 9$ \\
\hline $\begin{array}{l}\text { Chen Tao et al. } \\
\text { (19) }\end{array}$ & 2014 & China & NRCT & EGC & $\begin{array}{l}\mathrm{PO} \\
\mathrm{TO}\end{array}$ & $\begin{array}{l}26 \\
26\end{array}$ & $\begin{array}{l}62.34 \pm 0.13 \\
63.52 \pm 1.17\end{array}$ & $33 / 19$ & NA & NA & $5 / 9$ \\
\hline Wan et al. (21) & 2016 & China & $\mathrm{NRCT}$ & EGC & $\begin{array}{l}\mathrm{PO} \\
\mathrm{TO}\end{array}$ & $\begin{array}{l}33 \\
33\end{array}$ & NA & 37 / 29 & NA & NA & $6 / 9$ \\
\hline $\begin{array}{l}\text { Chen Deman et al. } \\
\text { (22) }\end{array}$ & 2014 & China & $\mathrm{NRCT}$ & EGC & $\begin{array}{l}\mathrm{PO} \\
\mathrm{TO}\end{array}$ & $\begin{array}{l}25 \\
25\end{array}$ & $\begin{array}{l}54.2 \pm 6.5 \\
56.2 \pm 7.8\end{array}$ & $34 / 16$ & NA & NA & $5 / 9$ \\
\hline Zhai et al. (18) & 2015 & China & $\mathrm{NRCT}$ & EGC & $\begin{array}{l}\mathrm{PO} \\
\mathrm{TO}\end{array}$ & $\begin{array}{l}36 \\
36\end{array}$ & $\begin{array}{l}55.56 \pm 1.16 \\
55.62 \pm 1.23\end{array}$ & $43 / 29$ & NA & NA & $5 / 9$ \\
\hline Ye et al. (20) & 2014 & China & NRCT & EGC & $\begin{array}{l}\mathrm{PO} \\
\mathrm{TO}\end{array}$ & $\begin{array}{l}5 \\
5\end{array}$ & NA & $5 / 5$ & Open & NA & $5 / 9$ \\
\hline Kim et al. (15) & 2011 & Korea & $\mathrm{NRCT}$ & EGC & $\begin{array}{l}\mathrm{PO} \\
\mathrm{TO}\end{array}$ & $\begin{array}{l}17 \\
20\end{array}$ & $\begin{array}{c}58.6 \pm 10.1 \\
58.2 \pm 9.5\end{array}$ & $28 / 9$ & Open & NA & $8 / 9$ \\
\hline Ha et al. (16) & 2008 & Korea & $\mathrm{NRCT}$ & EGC & $\begin{array}{l}\mathrm{PO} \\
\mathrm{TO}\end{array}$ & $\begin{array}{l}124 \\
992\end{array}$ & $\begin{array}{c}56.3 \pm 11.3 \\
57 \pm 11.3\end{array}$ & 768 / 348 & NA & NA & $8 / 9$ \\
\hline Kim et al. (23) & 2014 & Korea & NRCT & AGC & $\begin{array}{l}\mathrm{PO} \\
\mathrm{TO}\end{array}$ & $\begin{array}{l}66 \\
80\end{array}$ & $\begin{array}{l}62.2 \pm 11.0 \\
60.9 \pm 11.2\end{array}$ & $106 / 40$ & laparoscopic & 5 years & $8 / 9$ \\
\hline Hasegawa et al. (2) & 2013 & Korea & $\mathrm{NRCT}$ & AGC & $\begin{array}{l}\mathrm{PO} \\
\mathrm{TO}\end{array}$ & $\begin{array}{l}98 \\
98\end{array}$ & NA & $144 / 52$ & $\begin{array}{l}\text { Open / } \\
\text { laparoscopic }\end{array}$ & 5 years & $8 / 9$ \\
\hline Yamada et al. (24) & 2020 & Japan & $\mathrm{RCT}$ & AGC & PO/TO & 256 & NA & NA & Open & NA & $\begin{array}{l}\text { High } \\
\text { Risk }\end{array}$ \\
\hline
\end{tabular}

merely able to conduct a meta-analysis on 5-year relapse-free survival, because of the difference in survival indexes; we found no difference in 5- ear relapse-free survival between $\mathrm{TO}$ and $\mathrm{PO}$ $(\mathrm{OR}=0.799 ; 95 \% \mathrm{CI}: 0.484,1.320 ; \mathrm{P}=0.381)$. Furthermore, Hasegawa et al. (2) focused on 3-year relapse-free survival and 3 - and 5-year overall survival and found no statistical difference between TO and PO for advanced gastric cancer patients.

\section{Complications}

Nine studies including six on early cancer and three on advanced cancer provided 163 cases in total to further analysis on complications regardless of detailed types of complications. There was no significant difference in the incidence of complications between the two surgical procedures $(\mathrm{OR}=0.770$; 95\% CI: 0.533, 1.113; $P=0.164$ ) (Figure 2A).

\section{The Number of Retrieved Lymph Nodes}

Four studies provided the number of retrieved lymph nodes. Two types of omentectomy seemed to provide no difference in the number of retrieved lymph nodes (WMD $=1.265 ; 95 \% \mathrm{CI}$ : $-7.716,2.476 ; P=0.662$ ) (Figure 2B).

\section{Intraoperative Blood Loss}

Five studies provided data on intraoperative blood loss. Although there was no significant difference in intraoperative blood loss between the two kinds of omentectomy, partial omentectomy trended to reduce intraoperative bleeding $(\mathrm{WMD}=-47.301$; 95\% CI: $-94.683,3.961 ; P=0.050$ ) (Figure 2C).

\section{Time to First Flatus}

Four studies provided the time when the patient began to flatus after operation. Two types of omentectomy seemed to show no difference in the recovery of intestinal movement (WMD = 0.160; 95\% CI:-0.173, 0.493; P = 0.345) (Figure 2D).

\section{Operation Time}

Nine studies were analyzed by random-effects model, for the reason of heterogeneity $\left(I^{2}=88.1 \%, P=0.000\right)$. The operation time of PO was less than TO (WMD $=-25.584 ; 95 \% \mathrm{CI}$ : $-37.308,-13.860 ; P=0.000$ ) (Figure 2E).

\section{Postoperative Hospital-Stay}

Six studies focused on early gastric cancer were analyzed by random-effects model. There was no significant difference in length of hospital stay between the two types of omentectomy $(\mathrm{WMD}=-1.258 ; 95 \%$ CI: $-2.701,-0.184 ; P=0.087)$ (Figure 2F).

\section{Blood Infusion}

For patients with early gastric cancer, three studies gave the data on whether patients received blood transfusions during the operation. The result showed similar blood transfusions rates between $\mathrm{PO}$ and TO $(\mathrm{OR}=0.269 ; 95 \% \mathrm{CI}: 0.043,1.687 ; P=$ 0.161) (Figure 2G).

\section{Subgroup Analysis}

We performed the subgroup analysis stratified by stages (early gastric cancer vs. advanced gastric cancer). There were no significant differences in the incidence of complications (OR 
TABLE 2 | Outcome of survival, safety, operation-related events and subgroup analysis stratified by the operation method or stages.

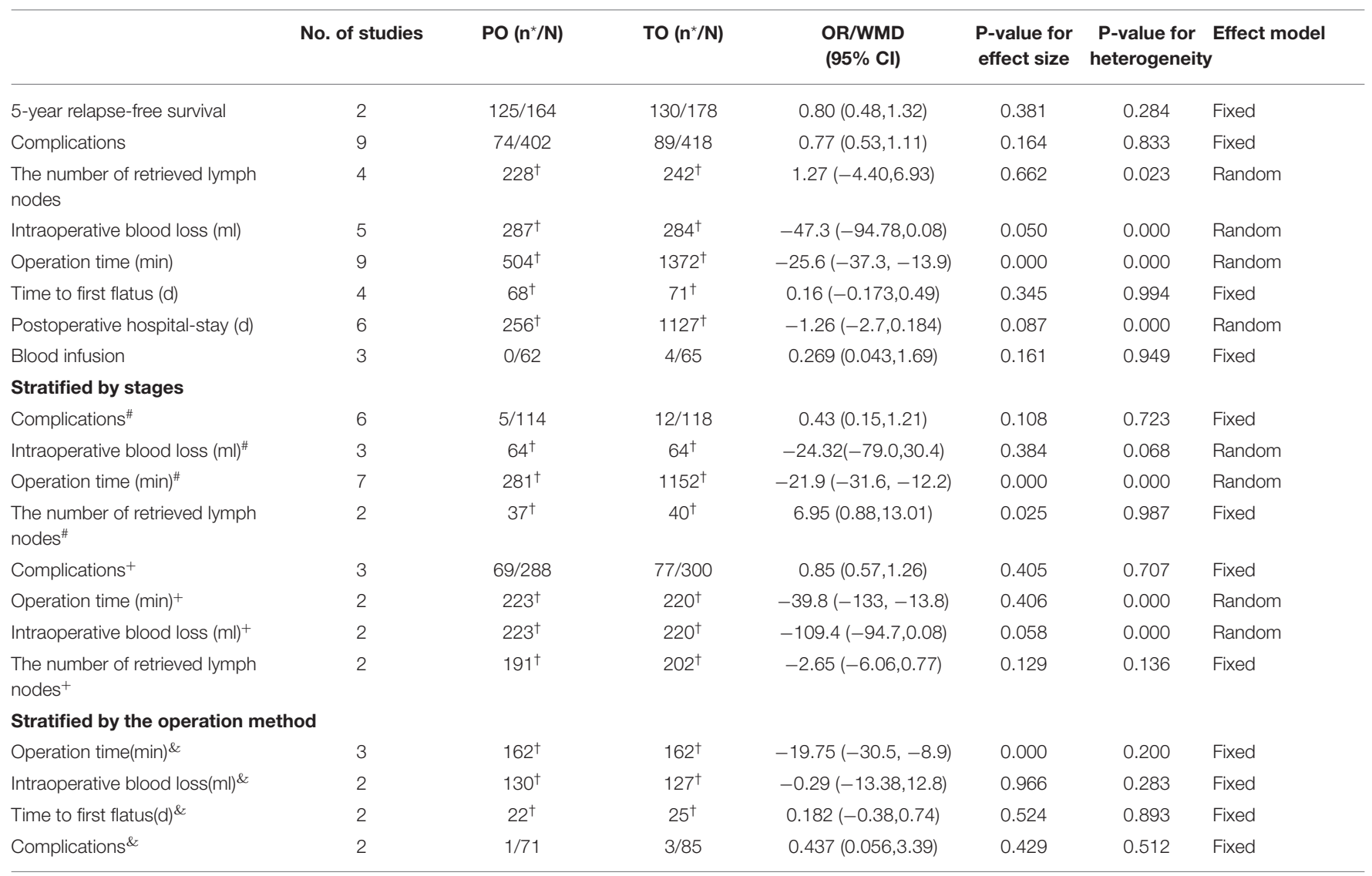

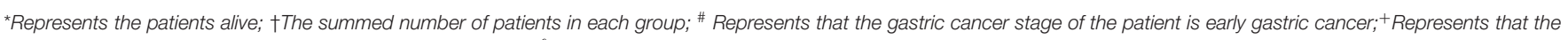

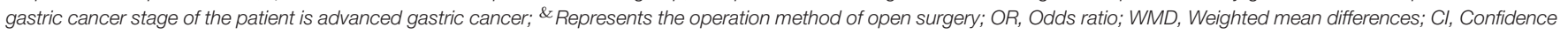
interval; PO, Partial omentectomy; TO, Total omentectomy; NA, Not applicable.

$=0.428 ; 95 \%$ CI: $0.152,1.205 ; P=0.108)$ and intraoperative blood loss (WMD $=-24.32$, 95\% CI: $-79.02,30.39, P=0.384$ ) in patients with early gastric cancer, but partial omentectomy cost less time (WMD $=-21.89 ; 95 \% \mathrm{CI}:-31.60,-12.19 ; P$ $=0.000$ ), and retrieved more lymph nodes (WMD $=6.95$; 95\% CI: $0.88,13.01 ; P=0.025)$ than total omentectomy. For patients with advanced gastric cancer, there were no significant differences between the two kinds of omentectomy in the incidence of complications ( $\mathrm{OR}=0.85 ; 95 \% \mathrm{CI}: 0.57$, 1.26; $P=0.405)$, operation time (WMD $=-25.58,95 \% \mathrm{CI}$ : $-133.75,54.09, P=0.406)$, and the number of retrieved lymph nodes (WMD $=-2.65,95 \% \mathrm{CI}:-6.06,0.77, P=$ 0.129). Furthermore, partial omentectomy trended to reduce intraoperative bleeding, although there was no significant difference in intraoperative blood loss between the two kinds of omentectomy (WMD $=-109.4,95 \% \mathrm{CI}:-94.7,0.08, P$ $=0.058)$.

Moreover, we also conducted the subgroup analysis stratified by the operation method (laparoscopic vs. open surgery). Only five articles included identified surgical procedures, four of which were performed by open surgery and one by laparoscopy. However, the four studies with open surgery reported different clinical parameters, and we were able to perform the meta-analysis on operative time, intraoperative blood loss, time to first flatus, and the incidence of complications. After analyzing four studies that provided essential information, we found that partial omentectomy cost less time than total omentectomy (WMD $=-19.754,95 \%$ CI: -30.517 , -8.992, $P=0.000$, Figure $2 \mathbf{H}$ ), but we could not find any differences in intraoperative blood loss (WMD $=-0.285$, 95\% CI: $-13.383,12.812, P=0.966)$, time to first flatus $(\mathrm{WMD}=0.182,95 \% \mathrm{CI}:-0.377,0.741, P=0.524)$, and the incidence of complications ( $\mathrm{OR}=0.437$; 95\% CI: 0.056, 3.399; $P=0.429)$.

\section{Sensitivity Analysis}

Sensitivity analysis showed that the conclusion remained unchanged after excluding each study one by one (Figure 3A).

\section{Publication Bias}

The funnel plot on the complications is presented in Figure 3B and shows that there was no evidence of publication bias. 
A

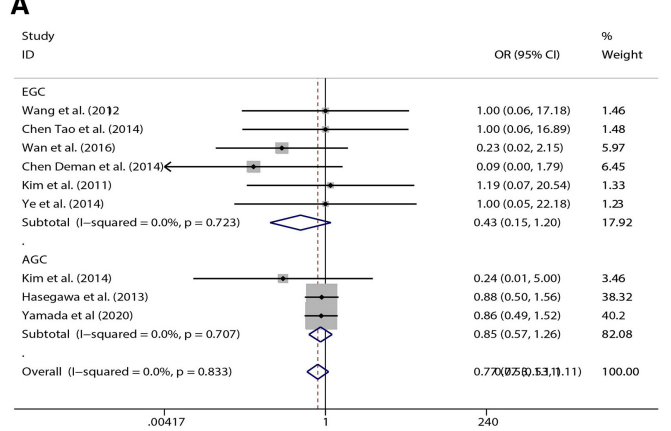

\section{C}

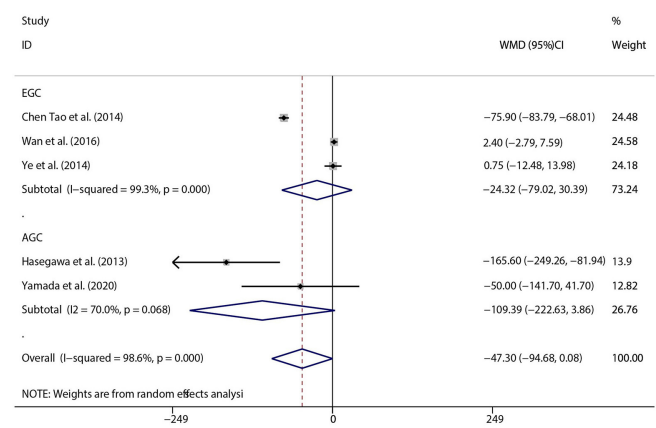

E

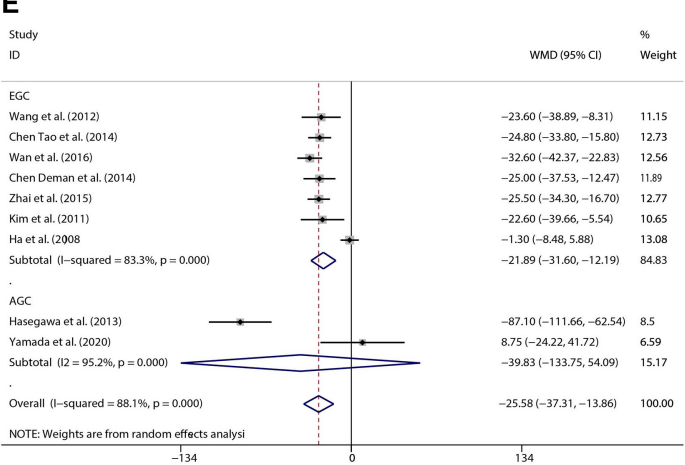

G

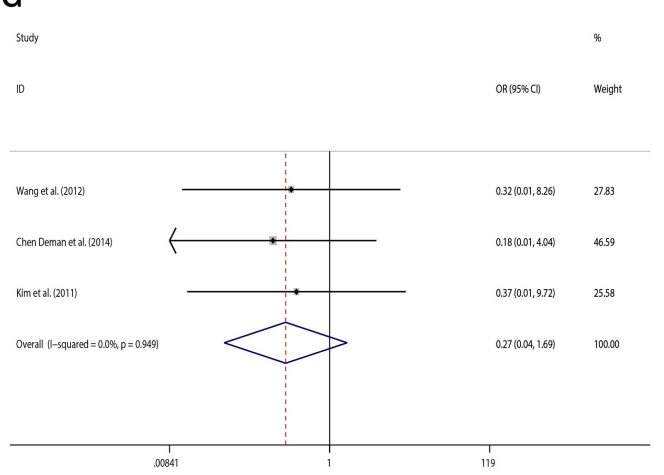

B

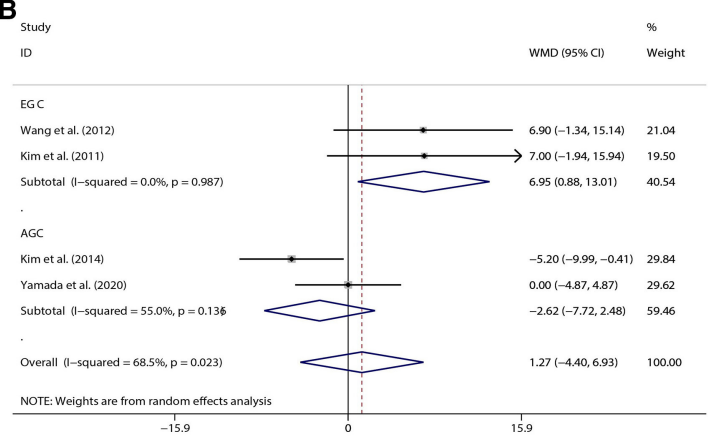

D

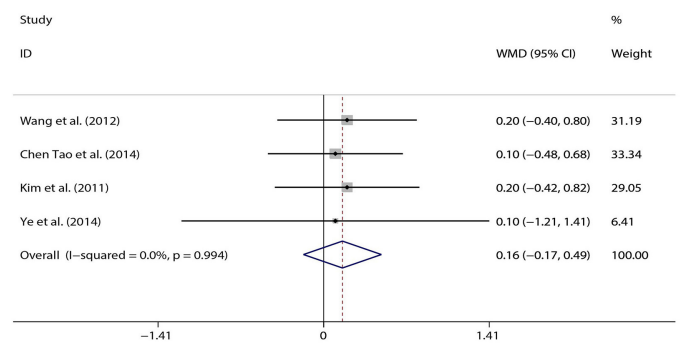

F

Stud

WMD (95\%C1) Weight

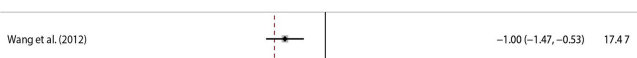

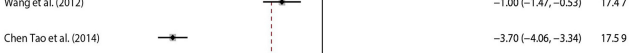

Wanetal. (2016)

zhai et al. (2015)

Kim et al. (2011)

Ha et al. (2008)

Overall (1-squared $=97.7 \%, p=0.000)$

NOTE: Weights are from random effects analysis

$-4.06$

$-130(-2.53,-0.07) \quad 15.75$

$-0.99(-2.77,0.73) \quad 14.21$

$-0.40(-0.92,0.12) \quad 17.40$

$-0.10(-0.48,0.28) \quad 17.58$

$-126(-2.70,0.18) \quad 100.00$

${ }_{4.06}^{1 .}$

H

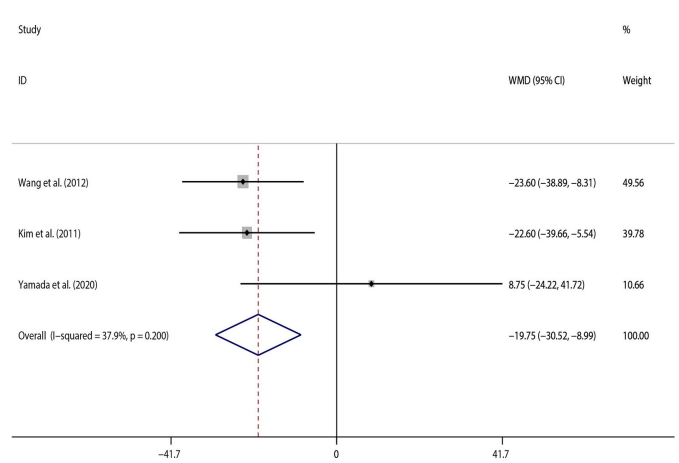

FIGURE 2 | Forest plots[(A) Complications, (B) The number of retrieved lymph nodes, (C) Intraoperative blood loss, (D) Time to first flatus, (E) Operation time, (F) Postoperative hospital stay, (G) Blood Infusion, (H) Comparison of operation time in open surgery]. 

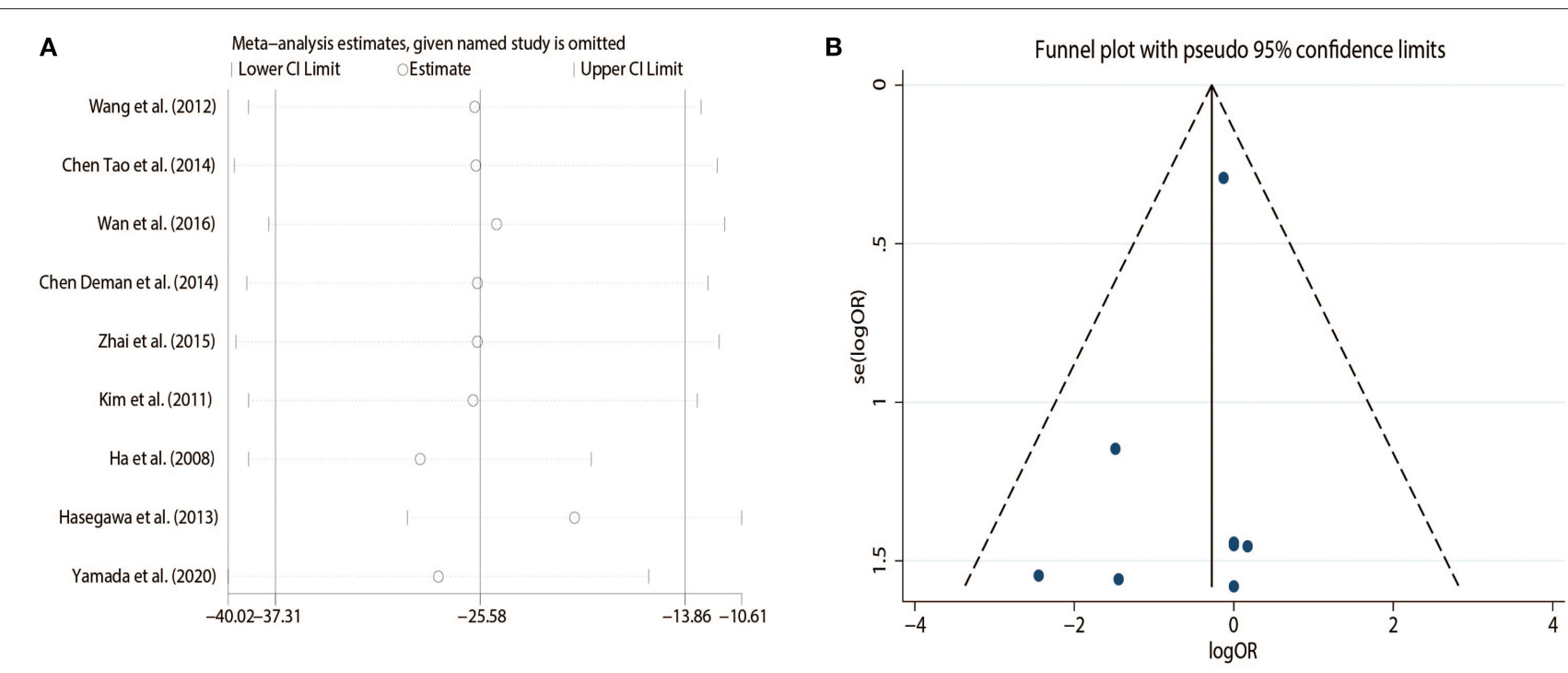

FIGURE 3 | (A) Sensitivity analysis on the operation time, (B) The funnel plot on the complications.

\section{DISCUSSIONS}

Since the metastatic rate of omental lymph nodes and possibility of omental micrometastasis of cancer cells are low in early gastric cancer, total omentectomy was not considered to provide more benefit than partial omentectomy for patients with T1/T2 gastric cancer. However, limited research focused on the comparison between partial omentectomy and total omentectomy in T3/T4 gastric cancer. Theoretically, total omentectomy seemed to offer the possibility of more complete lymph node dissection and elimination of micrometastasis of greater omentum in advanced gastric cancer. However, our study showed that total omentectomy had no obvious advantages in retrieving the lymph nodes. And the survival analysis showed that 5-year relapse-free survival was not higher for patients receiving TO than for those receiving PO. Since the included studies were limited, additional studies in the future about the impact of partial omentectomy on the extent of lymph node dissection and long-term survival are needed.

Considering the anatomical location and tissue composition of the greater omentum, total omentectomy is prone to injure the colon and spleen, while the omentum promotes angiogenesis through release of fibroblast growth factors and hence has a role in healing inflamed or ischemic tissue and reducing complications such as abdominal abscess, ascites, anastomotic leakage, intestinal obstruction, wound infection, and iatrogenic damage (25-27). However, our study could not draw the conclusion that partial omentectomy has lower complications than total omentectomy for early gastric cancer and advanced gastric cancer patients. The possible reason might be because there were differences in the complexity of the operation process among the patients and both of the two procedures could be safely performed by experienced skillful surgeons. As the result of RCT, there was no significant difference in the incidence of complications between the two procedures in patients with advanced gastric cancer. The safety between the TO and PO needs to be further verified. Nevertheless, partial omentectomy had shorter operation time and tendency of less intraoperative blood loss compared to total omentectomy, especially in the more complicated and time-wasting laparoscopic surgery, although there was only one study on laparoscopic study in the present metaanalysis.

There were some limitations in our study. Firstly, the number of relevant studies, especially large-scale RCT studies, were limited, and the sample sizes for the pooled metaanalyses were relatively small. In addition, the numbers of published studies on advanced gastric cancer or laparoscopic gastrectomy were inadequate. Hence, our findings must be interpreted and generalized cautiously. Secondly, data about the recurrence of gastric cancer and long-term survival outcomes was insufficient. More studies investigating the long-term prognosis of gastric cancer patients between TO and PO are needed. Thirdly, some data was obtained through indirect methods, such as some means and standard deviations from the median and interquartile range, which can impair the accuracy of results. Although limitations were inevitable, we made efforts to minimize the biases by developing a detailed protocol, performing a cautious search, using objective methods for study selection, data extraction, and analysis, and performing the subgroup analyses and sensitivity analyses.

In conclusion, the partial omentectomy had advantages in reducing operation time and trended to decrease intraoperative blood loss. And the survival in patients with partial omentectomy seemed to be comparable to that of patients with total omentectomy. Comparisons of the 
survival and safety between total omentectomy and partial omentectomy for gastric cancer needs to be further explored in large-scale RCTs.

\section{DATA AVAILABILITY STATEMENT}

The original contributions presented in the study are included in the article/supplementary material, further inquiries can be directed to the corresponding author.

\section{AUTHOR CONTRIBUTIONS}

Y-XZ and H-DL: study conception and design, acquisition of data, and drafting of manuscript. Y-XZ, Z-HC, and TJ: analysis

\section{REFERENCES}

1. Lawrance RJ, Loizidou M, Cooper AJ, Alexandar P, Taylor I. Importance of the omentum in the development of intra-abdominal metastases. Br J Surg. (1991) 78:1179. doi: 10.1002/bjs.1800780135

2. Hasegawa S, Kunisaki C, Ono H, Oshima T, Fujii S, Taguri M, et al. Omentum-preserving gastrectomy for advanced gastric cancer: a propensitymatched retrospective cohort study. Gastric Cancer. (2013) 16:383-8. doi: 10.1007/s10120-012-0198-6

3. Pereira MA, Ramos MFKP, Dias AR, Yagi OK, Faraj SF, Zilberstein B, et al. Detection of occult lymph node tumor cells in node-negative gastric cancer patients. ABCD Arq Bras Cir Dig. (2017) 30:30-4. doi: 10.1590/0102-6720201700010009

4. Barchi LC, Ramos MFKP, Dias AR, Yagi OK, Ribeiro-Júnior U, Zilberstein $\mathrm{B}$, et al. Total omentectomy in gastric cancer surgery: Is it always necessary? ABCD Arq Bras Cir Dig. (2019) 32:e1425. doi: 10.1590/0102-672020180001e1425

5. Van Cutsem E, Dicato M, Geva R, Arber N, Bang Y, Benson A, et al. The diagnosis and management of gastric cancer: expert discussion and recommendations from the 12th ESMO/World Congress on Gastrointestinal Cancer, Barcelona, 2010. Ann Oncol. (2011) 22(Supplement 5):v1-9. doi: 10.1093/annonc/mdr284

6. Fujita J, Tsukahara Y, Ikeda K, Akagi K, Kan K, Hata S, et al. Evaluation of Omentum Preserving Gastrectomy for Advanced Gastric Cancer. Japanese J Gastroenterol Surg. (2003) 36:1151-8. doi: 10.5833/jjgs.36.1151

7. Jongerius EJ, Boerma D, Seldenrijk KA, Meijer SL, Scheepers JJ, Smedts F, et al. Role of omentectomy as part of radical surgery for gastric cancer. Br J Surg. (2016) 103:1497-503. doi: 10.1002/bjs.10149

8. NCCN Clinical Practice Guidelines in Oncology-gastric cancer (2020 Version I) $[\mathrm{DB} / \mathrm{OL}]$.

9. Smyth EC, Verheij M, Allum W, Cunningham D, Cervantes A, Arnold D, et al. Gastric cancer: ESMO Clinical Practice Guidelines for diagnosis, treatment and follow-up. Ann Oncol. (2016) 27:v38-49. doi: 10.1093/annonc/mdw350

10. Japanese Gastric Cancer Association. Japanese gastric cancer treatment guidelines 2014 (ver. 4). Gastric Cancer 20, 1-19 (2017). doi: 10.1007/s10120-016-0622-4

11. Liberati A, Altman DG, Tetzlaff J, Mulrow C, Gøtzsche PC, Ioannidis JP, et al. The PRISMA statement for reporting systematic reviews and meta-analyses of studies that evaluate healthcare interventions: explanation and elaboration. BMJ. (2009) 339:b2700. doi: 10.1136/bmj.b2700

12. Stroup DF, Berlin JA, Morton SC, et al. Meta-analysis of observational studies in epidemiology: a proposal for reporting. Meta-analysis Of Observational Studies in Epidemiology (MOOSE) group. JAMA. (2000) 283:2008-12. doi: 10.1001/jama.283.15.2008

13. Higgins JPT, Savović J, Page MJ, Elbers RG, Sterne JAC. Chapter 8: Assessing risk of bias in a randomized trial. In: Higgins JPT, Thomas J, Chandler J, Cumpston M, Li T, Page MJ, Welch VA (editors). Cochrane Handbook for and interpretation of data. $\mathrm{KY}$ and $\mathrm{J}-\mathrm{KH}$ : critical revision of manuscript. All authors contributed to the article and approved the submitted version.

\section{FUNDING}

Domestic support from (1) National Natural Science Foundation of China (No. 81772547); (2) the Fundamental Research Funds for the central Universities (No. 2017SCU04A18); (3) Young scientific and academic leaders training program of Sichuan University (No. 0082604151001/035); (4) Foundation of Science and Technology Department of Sichuan Province (No. 2019YFS0256); (5) 1. 3.5 project for disciplines of excellence, West China Hospital, Sichuan University (No. ZY2017304).

Systematic Reviews of Interventions version 6.0 (updated July 2019). Cochrane (2019). doi: 10.1002/9781119536604.ch8

14. Hozo SP, Djulbegovic B, Hozo I. Estimating the mean and variance from the median, range, and the size of a sample. BMC Med Res Methodol. (2005) 5:13. doi: 10.1186/1471-2288-5-13

15. Kim MC, Kim KH, Jung GJ, Rattner DW. Comparative study of complete and partial omentectomy in radical subtotal gastrectomy for early gastric cancer. Yonsei Med J. (2011) 52:961-6. doi: 10.3349/ymj.2011.5 2.6.961

16. Ha TK, An JY, Youn HG, Noh JH, Sohn TS, Kim S. Omentum-preserving gastrectomy for early gastric cancer. World J Surg. (2008) 32:1703-8. doi: 10.1007/s00268-008-9598-5

17. Xianglong Wang. Comparison of the effect of complete and partial omentectomy in subtotal resection of early gastric cancer. Journal of Bengbu Medical College. (2012) 1300-2. doi: 10.13898/j.cnki.issn.1000-2200.2012.11.051

18. Yong Zhai. Clinical value of complete and partial omentectomy in subtotal resection of early gastric cancer. Guide Chin Med. (2015) 59-60. doi: 10.15912/j.cnki.gocm.2015.14.039

19. Tao Chen, Zhigang Cao. Comparison of clinical efficacy between complete and partial omentectomy in subtotal resection of early gastric cancer. (2014) 4634. doi: 10.3969/j.issn.1009-6019(z).2014.06.329

20. Yahuai Ye. Comparison of clinical efficacy between complete and partial omentectomy in subtotal resection of early gastric cancer. For all Health. 2014:182-3. doi: 10.3969/j.issn.1009-6019(x).2014.03.212

21. Yi Wan. Comparison of clinical efficacy between complete and partial omentectomy in subtotal resection of early gastric cancer. Chinese and Foreign Medical Research. 2016:133-4. doi: 10.14033/j.cnki.cfmr.2016.3.073

22. Deman Chen. Comparison of clinical efficacy between complete and partial omentectomy in subtotal resection of early gastric cancer. Modern Diagnosis and Treatment. 2014:1588-9. doi: 10.1160/r.issn.1001-8174.2014.07.109

23. Kim D, Lee J, Kim W. A comparison of total versus partial omentectomy for advanced gastric cancer in laparoscopic gastrectomy. World J Surg Oncol. (2014) 12:64. doi: 10.1186/1477-7819-12-64

24. Yamada T, Murakami H, Taguri M, Hasegawa S, Yamanaka T, Rino Y, et al. The short-term outcomes from TOP-G trial: Ramdomized phase II noninferiority trial comparing gastrectomy with omentectomy and omentum preserving gastrectomy for advanced gastric cancer. J Clin Oncol. (2020) 38. doi: 10.1200/JCO.2020.38.4_suppl.285

25. $\mathrm{Li} \mathrm{J}, \mathrm{Xu} \mathrm{P}$, Chen $\mathrm{H}$, Yang $\mathrm{Z}$, Zhang $\mathrm{Q}$. Improvement of tracheal autograft survival with transplantation into the greater omentum. Ann Thorac Surg Dec. (1995) 60:1592-6. doi: 10.1016/0003-4975(95)0 0839-X

26. Shoshany G, Mordohovich D, Lichtig H, Bar-Maor JA. Preserved viability of the isolated bowel segment, created by omentoenteropexy: a histological observation. J Pediatr Surg September. (1995) 30:1291-3. doi: 10.1016/0022-3468(95)90487-5 
27. Ben Arie A, McNally L, Kapp DS, Teng NN. The omentum and omentectomy in epithelial ovarian cancer: a reappraisal. Part I-Omental function and history of omentectomy. Gynecol Oncol. (2013) 131:780-3. doi: 10.1016/j.ygyno.2013.09.014

Conflict of Interest: The authors declare that the research was conducted in the absence of any commercial or financial relationships that could be construed as a potential conflict of interest.

Publisher's Note: All claims expressed in this article are solely those of the authors and do not necessarily represent those of their affiliated organizations, or those of the publisher, the editors and the reviewers. Any product that may be evaluated in this article, or claim that may be made by its manufacturer, is not guaranteed or endorsed by the publisher.

Copyright $\odot 2021$ Zhang, Liu, Chen, Jin, Hu and Yang. This is an open-access article distributed under the terms of the Creative Commons Attribution License (CC $B Y)$. The use, distribution or reproduction in other forums is permitted, provided the original author(s) and the copyright owner(s) are credited and that the original publication in this journal is cited, in accordance with accepted academic practice. No use, distribution or reproduction is permitted which does not comply with these terms. 